\section{Effect of corticosteroid use by dose on the risk of developing organ damage over time in systemic lupus erythematosus - the Hopkins Lupus Cohort}

Sarah Al Sawah, ${ }^{1}$ Xiang Zhang, ${ }^{1}$ Baojin Zhu, ${ }^{1}$ Laurence S Magder, ${ }^{2}$ Shonda A Foster, ${ }^{1}$ Noriko likuni, ${ }^{1}$ Michelle Petri ${ }^{3}$
To cite: Al Sawah S,

Zhang X, Zhu B, et al. Effect of corticosteroid use by dose on the risk of developing organ damage over time in systemic lupus erythematosus-the Hopkins Lupus Cohort. Lupus Science \& Medicine 2015;2:e000066. doi:10.1136/lupus-2014000066

Received 24 October 2014 Revised 16 February 2015 Accepted 18 February 2015

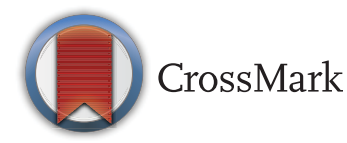

${ }^{1}$ Eli Lilly and Company, Indianapolis, Indiana, USA ${ }^{2}$ University of Maryland School of Medicine, Baltimore, Maryland, USA

${ }^{3}$ The Johns Hopkins University School of Medicine, Baltimore, Maryland, USA

Correspondence to Dr Sarah Al Sawah; al_sawah_sarah@lilly.com

\section{ABSTRACT}

Objectives: The impact of corticosteroids on the risk of organ damage in the context of clinical end points endorsed in some systemic lupus erythematosus (SLE) clinical trials is underexplored.

Methods: We analysed data from the Hopkins Lupus Cohort using Cox proportional hazards models to understand the impact of exposure to different corticosteroid doses on the risk of developing any new organ damage or any new organ damage at the individual organ systems over time.

Results: Mean prior prednisone dose, recent disease activity and immunosuppressant use during follow-up, as well as organ damage score at cohort entry, were significant independent predictors of the risk of developing any new organ damage. Even after adjustment for recent disease activity, there was a dose-response relationship across the different levels of exposure to prednisone during follow-up and the risk of developing any new organ damage. The risk more than doubled in patients exposed to a mean prior prednisone dose of $\geq 20 \mathrm{mg} /$ day versus $<7.5 \mathrm{mg} /$ day $(\mathrm{HR}=2.514, \mathrm{p}<0.001)$. It was estimated that a $1 \mathrm{mg} /$ day increase in prior prednisone dose during follow-up was associated with a $2.8 \%$ increase in the risk of developing new organ damage. For individual organ systems, exposure to a mean prior prednisone dose of $\geq 7.5 \mathrm{mg} /$ day versus $<7.5 \mathrm{mg} /$ day significantly increased the risk of developing cataracts $(\mathrm{HR}=2.41$, $p<0.001)$, osteoporotic fractures $(H R=2.16, p<0.001)$ and cardiovascular damage ( $H R=1.54, p=0.041)$, but showed no significant difference for renal damage ( $H R=1.44, p=0.163$ ) or for other individual organ systems.

Conclusions: Organ damage in SLE is multifactorial; corticosteroid treatment and disease activity play a role.

\section{INTRODUCTION}

Reduction of corticosteroid dose remains an important goal in the management of systemic lupus erythematosus (SLE). Chronic

\section{KEY MESSAGES}

- Organ damage in SLE is multifactorial; both corticosteroid treatment and disease activity play a role.

- A reduction of as little as $1 \mathrm{mg} /$ day in mean prednisone dose reduces the estimated risk of future organ damage by $3 \%$.

corticosteroid use is associated with the accrual of irreversible organ damage over time, with the highest risk being among those exposed to a mean prednisone dose of $\geq 20 \mathrm{mg} /$ day. $^{1}{ }^{2}$ A previous analysis from the Hopkins Lupus Cohort demonstrated that the risk of developing later organ damage increases by $50 \%$ when patients were exposed to an average cumulative prednisone dose of $>6-12 \mathrm{mg} /$ day compared with little to no exposure $(>0$ $6 \mathrm{mg} /$ day) to prednisone. ${ }^{3}$ In addition, a similar analysis using the same cohort demonstrated a significant association between corticosteroid use and the risk of developing new cardiovascular damage over time, while controlling for important clinical measures including disease activity, as well as traditional risk factors of cardiovascular diseases. ${ }^{4}$

There are no analyses completed to date that account for either the disease activity score cut-off points or the corticosteroid dose cut-off points endorsed in some of the SLE clinical trials and how those dose levels may translate to the risk of overall organ damage or organ damage at the individual organ systems in SLE.

Therefore, we used Cox proportional hazards models to estimate the impact of different levels of exposure to corticosteroids (as defined by corticosteroid cut-off points 
endorsed in some SLE clinical trials) on the risk of developing any new organ damage or any new organ damage at the individual organ systems over time. Organ damage was measured by the Systemic Lupus International Collaborating Clinics/American College of Rheumatology Damage Index (SDI) or by components of the SDI at the individual organ systems level.

Understanding the association of corticosteroid use by dose to the accrual of organ damage overall and organ damage of individual organ systems over time would help clinicians estimate the long-term benefit gained from the use of corticosteroid-sparing therapies, beyond the benefit gained from controlled disease activity.

\section{METHODS}

\section{Data source}

The Hopkins Lupus Cohort is a prospective longitudinal study that has followed patients with SLE through quarterly (or more frequent) visits since $1987 .{ }^{1}$ All patients are followed by a standardised protocol of disease activity indices (Physician Global Assessment, Lupus Activity Index, and Safety of Estrogens in Lupus Erythematosus National Assessment version of the SLE Disease Activity Index (SELENA-SLEDAI)) and laboratory tests. The patients with SLE entered into the cohort have provided informed consent, and any use of the cohort's data is done in accordance with the Declaration of Helsinki. Because of its size (more than 2000 patients) and longitudinal design (mean duration of follow-up is $\sim 6$ years), the Hopkins Lupus Cohort provides an opportunity to assess the relationship between corticosteroid use and organ damage in this population with relative precision. ${ }^{45}$

At the time of this analysis, the cohort included 2265 patients with SLE who were followed over the course of 26 years between 1987 and October 2012, with the average duration of follow-up from cohort entry until lost to follow-up being 6.2 years. Only patients younger than 18 years and those with no follow-up data beyond their initial visit were excluded from this study, rendering the sample size for this analysis at 2199 patients with SLE.

The SDI, a validated instrument designed to measure irreversible organ damage in 12 different organ systems in patients with SLE, was used to identify any new organ damage over time. ${ }^{6} 7$ The SDI captures irreversible organ damage, since lupus diagnosis, that is associated with the disease itself, its treatment (including corticosteroid use), or neither. Multiple studies have used the SDI to examine disease variables associated with organ damage. ${ }^{18-12}$

The SELENA-SLEDAI was used to measure overall disease activity. ${ }^{13}$ The SELENA-SLEDAI score was included in the Cox proportional hazards model as a two-level variable. A predefined cut-off point of 6 was selected based on what has been endorsed for SELENA-SLEDAI entry criteria in some SLE clinical trials. Similarly, the cut-off point for prednisone dose was selected at $7.5 \mathrm{mg} /$ day; however, a few additional prednisone cut-off points were also evaluated.

\section{Statistical analysis}

Baseline demographics and clinical characteristics were analysed for the overall study sample $(\mathrm{N}=2199)$ and for subgroups of patients with SELENA-SLEDAI score $<6$ $(\mathrm{N}=1643)$ and SELENA-SLEDAI score $\geq 6 \quad(\mathrm{~N}=528)$ at baseline. The rate of any organ damage and the rate of any organ damage at the individual organ systems, as well as the rate of first occurring new organ damage and the rate of first occurring new organ damage at the individual organ systems, during follow-up were calculated.

A Cox proportional hazards model was developed to assess the relationship between mean prior prednisone dose during follow-up and the risk of developing any new organ damage or organ damage at the individual organ systems (ie, cataracts, osteoporotic fractures, cardiovascular damage and renal damage) since cohort entry. The Cox model only accounts for first occurrence of new organ damage or first occurrence of new organ damage at the individual organ systems during follow-up. Time-invariant and time-dependent variables were included in the model. To precisely assess the impact of time-dependent variables (recent disease activity and prior prednisone dose) on the risk of organ damage, we reformatted the data set to consist of one record for each quarter (ie, person-quarter record), which is consistent with the cohort's data collection frequency set by the Hopkins Lupus Cohort protocol (ie, quarterly). For each person-quarter record (which was set as a fixed date at the last day of each quarter in a given year) timedependent variables were recorded based on the most recent visit record prior to each person-quarter record. These time-dependent variables included mean prior daily prednisone dose (calculated as the average prednisone dose during prior cohort follow-ups from cohort entry up to the most recent visit prior to each personquarter record); recent SELENA-SLEDAI score (updated for each person-quarter record, based on the most recent visit prior to each person-quarter record); immunosuppressant use (updated for each personquarter record, based on whether a patient has been on an immunosuppressant any time during follow-up from cohort entry up to the most recent visit prior to each person-quarter record); antimalarial use (updated for each person-quarter record, based on whether a patient has been on an antimalarial any time during follow-up from cohort entry up to the most recent visit prior to each person-quarter record); recent body mass index (based on the most recent visit prior to each personquarter record); and recent cholesterol level (based on the most recent visit prior to each person-quarter record). The history of comorbid conditions (ie, hypertension, diabetes and renal damage) was recorded based on the absence or presence of these conditions prior to each person-quarter record. A flare, which is a measure of acute change in disease activity, was not included in the model as it is highly collinear with the timedependent disease activity variable of 'SELENA-SLEDAI score' that is updated at each person-quarter record. 
For the overall model estimating the risk for developing any new organ damage over time, patients were followed from cohort entry until one of the following end points (whichever occurred first): (1) 826 patients were followed until the date the first irreversible organ damage occurred; (2) 1304 were censored at the date when the patient dropped from the cohort; and (3) 67 were censored at 15 years after cohort entry.

For the cataract model, patients were followed from cohort entry until one of the following end points (whichever occurred first): (1) 196 patients were followed until the date the first cataract event occurred; (2) 1831 were censored at the date when the patient dropped from the cohort; and (3) 170 were censored at 15 years after cohort entry.

For the cardiovascular model, patients were followed from cohort entry until one of the following end points (whichever occurred first): (1) 128 patients were followed until the date the first cardiovascular event occurred; (2) 1887 were censored at the date when the patient dropped from the cohort; and (3) 182 were censored at 15 years after cohort entry.

For the fracture model, patients were followed from cohort entry until one of the following end points (whichever occurred first): (1) 177 patients were followed until the date the first fracture event occurred; (2) 1843 were censored at the date when the patient dropped from the cohort; and (3) 177 were censored at 15 years after cohort entry.

For the renal model, patients were followed from cohort entry until one of the following end points (whichever occurred first): (1) 75 patients were followed until the date the first renal damage occurred; (2) 1927 were censored at the date when the patient dropped from the cohort; and (3) 195 were censored at 15 years after cohort entry.

For the overall model estimating the risk for developing any new organ damage or for any of the models of individual organ systems, the analysis was truncated at 15 years of follow-up after cohort entry because less than $10 \%$ of patients had a follow-up longer than 15 years.

Furthermore, since the study sample included in this analysis $(\mathrm{N}=2199)$ is not fully an inception sample (29.2\% entered the Hopkins cohort within the 1st year of diagnosis, $37.8 \%$ between $1-5$ years of diagnosis and $33.0 \%$ after 5 years of diagnosis), and the analyses completed did not account for corticosteroid exposure prior to cohort entry, a sensitivity analysis for the overall model estimating the risk for developing any new organ damage over time was repeated using the proportion of patients who have entered the Hopkins cohort within the 1st year $(n=642,29.2 \%)$ and within the 2nd year $(\mathrm{n}=944,42.9 \%)$ of their SLE diagnosis.

\section{RESULTS}

Baseline demographics and clinical characteristics

Demographic and disease characteristics at cohort entry are summarised in table 1. At cohort entry, the mean age of the study sample was 38.0 years. The mean duration of SLE was 5.1 years, with $29.2 \%$ of patients entering the cohort within their 1st year of diagnosis and $42.9 \%$ of patients entering the cohort within their 2nd year of diagnosis. Of the 2199 patients with SLE, 92.5\% were female, $55.3 \%$ were white and $37.6 \%$ were black. The treatment profiles at cohort entry included $19.2 \%$ of patients receiving an immunosuppressant drug, $70.3 \%$ receiving hydroxychloroquine, and $52.7 \%$ receiving corticosteroids (of which $40.2 \%$ were receiving a prednisone dose $\geq 7.5 \mathrm{mg}$ /day). Patients could be receiving more than one type of SLE treatment at cohort entry. The average overall SELENA-SLEDAI score at cohort entry was 3.5 (of which $24.3 \%$ had a SELENA-SLEDAI score $\geq 6$ ). Only $50.5 \%$ of the study sample had any type of organ damage at cohort entry, with a mean SDI score of 1.2.

Distribution of the rate of any organ damage and any organ damage at the individual organ systems during follow-up Overall, the most frequent types of organ damage occurring over time were musculoskeletal damage (20.3\%) and ocular damage (15.8\%) (table 2). Osteoporotic fractures represented $12.4 \%$ of the total number of organ damage events, while cataracts represented $13.7 \%$ of the total number of organ damage events. When assessing the rates of first organ damage events by organ system, the number of events for musculoskeletal damage $(20.3 \%)$ and ocular damage $(16.3 \%)$ were the highest. This result suggested that these corticosteroid-related comorbidities might present prior to any other type of organ damage in patients with SLE over time.

\section{Cox proportional hazards models for any new organ damage}

From the Cox proportional hazards models, age at cohort entry, SDI score at cohort entry, mean prednisone dose during follow-up, recent SELENA-SLEDAI score during follow-up, year of SLE diagnosis and immunosuppressant use during follow-up were significant predictors of any new organ damage $(p<0.05)$ (table 3). From a preliminary Cox proportional hazards model, not included in this paper, we demonstrated that neither SELENA-SLEDAI score at cohort entry nor immunosuppressant use at cohort entry were significant predictors of any new organ damage over time and, therefore, were not included in the final models.

From Model 1, patients exposed on average to prior prednisone dose $\geq 7.5 \mathrm{mg}$ /day over time had 1.742 times the risk of developing any new organ damage as compared with those exposed on average to prior prednisone dose $<7.5 \mathrm{mg} /$ day $\quad(\mathrm{HR}=1.742, \mathrm{p}<0.001)$ (table 3). From Model 2, the estimated risk of developing any new organ damage over time increased linearly as the exposure to a higher mean prior prednisone dose increased over time. The subgroup of patients exposed on average to prior prednisone dose $\geq 20 \mathrm{mg}$ / day over time had more than two times the risk of developing any new organ damage, as compared with 
Table 1 Baseline characteristics of the study cohort

\begin{tabular}{|c|c|c|c|}
\hline Baseline characteristics & $\begin{array}{l}\text { All patients } \\
(\mathrm{N}=2199)\end{array}$ & $\begin{array}{l}\text { SELENA-SLEDAI <6 } \\
(\mathrm{N}=1643)\end{array}$ & $\begin{array}{l}\text { SELENA-SLEDAI } \geq 6 \\
(\mathrm{~N}=528)\end{array}$ \\
\hline Mean age, years & 32.9 & 33.8 & 30.1 \\
\hline Mean age at cohort entry, years & 38.0 & 39.0 & 35.2 \\
\hline \multicolumn{4}{|l|}{ Gender, n (\%) } \\
\hline Male & $165(7.50)$ & $126(7.67)$ & $37(7.01)$ \\
\hline Female & $2034(92.50)$ & $1517(92.33)$ & $491(92.99)$ \\
\hline \multicolumn{4}{|l|}{ Race, n (\%) } \\
\hline White & $1215(55.25)$ & $965(58.73)$ & $232(43.94)$ \\
\hline Black & $827(37.61)$ & $558(33.96)$ & $261(49.43)$ \\
\hline Asian & $74(3.37)$ & $58(3.53)$ & $15(2.84)$ \\
\hline Other & $83(3.77)$ & $62(3.77)$ & $20(3.79)$ \\
\hline Mean SDI score at cohort entry & 1.2 & 1.1 & 1.3 \\
\hline Mean SELENA-SLEDAI score at cohort entry & 3.5 & 1.7 & 9.2 \\
\hline \multicolumn{4}{|l|}{ Prednisone use at cohort entry, $\mathrm{n}(\%)^{*}$} \\
\hline Yes & $1144(52.72)$ & $755(46.04)$ & $387(73.30)$ \\
\hline No & $1026(47.28)$ & $885(53.96)$ & $141(26.70)$ \\
\hline \multicolumn{4}{|l|}{ Year of SLE diagnosis, $\mathrm{n}(\%)$} \\
\hline Pre-1980s & $143(6.50)$ & $98(5.96)$ & $44(8.33)$ \\
\hline 1980s & $408(18.55)$ & $270(16.43)$ & $134(25.38)$ \\
\hline 1990s & $826(37.56)$ & $621(37.80)$ & $190(35.98)$ \\
\hline $2000 s$ & $822(37.38)$ & $654(39.80)$ & $160(30.30)$ \\
\hline \multicolumn{4}{|l|}{ Time since SLE diagnosis } \\
\hline Mean, years & 5.1 & 5.2 & 5.1 \\
\hline$<1, \mathrm{n}(\%)$ & $642(29.20)$ & $478(29.09)$ & $154(29.17)$ \\
\hline $1-5, \mathrm{n}(\%)$ & 831 (37.79) & $641(39.01)$ & $179(33.90)$ \\
\hline$>5, \mathrm{n}(\%)$ & 726 (33.02) & 524 (31.89) & 195 (36.93) \\
\hline \multicolumn{4}{|l|}{ Follow-up, years, (n \%) } \\
\hline$<1$ & 489 (22.24) & $374(22.76)$ & $111(21.02)$ \\
\hline $1-5$ & 687 (31.24) & $530(32.26)$ & $151(28.60)$ \\
\hline $5-10$ & 489 (22.24) & $374(22.76)$ & $103(19.51)$ \\
\hline$>10$ & $534(24.28)$ & $365(22.22)$ & $163(30.87)$ \\
\hline Mean follow-up, years & 6.2 & 5.9 & 7.2 \\
\hline Mean dropout rate per year, \% & 16.1 & 17.1 & 13.9 \\
\hline
\end{tabular}

those exposed on average to prior prednisone dose $<7.5 \mathrm{mg} /$ day $(\mathrm{HR}=2.514, \mathrm{p}<0.001)$.

In Model 3, we handled mean prior prednisone dose during follow-up as a continuous variable, rather than categorical, to further investigate the dose-response relationship between mean prior prednisone dose and the risk of developing any new organ damage over time (table 3). With every $1 \mathrm{mg}$ increase in average daily prednisone dose, irrespective of baseline prednisone dose, the risk of developing any new organ damage increased by approximately $3 \% \quad(\mathrm{HR}=1.028, \mathrm{p}<0.001)$, which translates to a $15 \%(\mathrm{HR}=1.150,95 \%$ CI 1.112 to $1.188, \mathrm{p}<0.001)$ increased risk associated with an average of a $5 \mathrm{mg}$ /day increase in prior prednisone dose.

When the Model 1 analysis was restricted to patients who entered the Hopkins cohort within a year or two of their SLE diagnosis (Models 4 and 5), the main findings were similar to those seen with the full cohort in Model 1 (table 4).
Cox proportional hazards models at the individual organ systems

We further examined the impact of different levels of exposure to prior prednisone on the risk of developing any new organ damage at the individual organ systems, as defined by the 12 components of the SDI. In this paper, we report only the models of four individual types of organ damage (ie, cataracts, osteoporotic fractures, cardiovascular damage and renal damage) (table 5).

For the cataract model, mean prior prednisone dose during follow-up $(\mathrm{HR}=2.412, \quad \mathrm{p}<0.001)$ and recent SELENA-SLEDAI score during follow-up (HR=1.475, $\mathrm{p}=0.045$ ) were significantly positively associated with the risk of developing cataracts in this relatively young patient population (table 5). The osteoporotic fracture model was consistent with the finding from the cataract model, in that the risk of osteoporotic fractures was driven by mean prior prednisone dose during follow-up; however, in this model, the relationship between 
Table 2 Distribution of any and first organ damage and organ damage by organ system during follow-up

\begin{tabular}{lcc}
\hline & Any organ damage & First organ damage \\
& N (\%) & N $\%)$ \\
\hline Any organ damage (total) & $1428(100.0)$ & $826(100.00)$ \\
Ocular damage & $225(15.76)$ & $135(16.34)$ \\
Cataract damage & $196(13.73)$ & $116(14.04)$ \\
Neuropsychiatric damage & $191(13.38)$ & $128(15.50)$ \\
Stroke & $57(3.99)$ & $28(3.39)$ \\
Renal damage & $75(5.25)$ & $51(6.17)$ \\
Pulmonary damage & $165(11.55)$ & $94(11.38)$ \\
Pulmonary fibrosis & $90(6.30)$ & $48(5.81)$ \\
Cardiovascular damage & $128(8.96)$ & $55(6.66)$ \\
Peripheral damage & $46(3.22)$ & $21(2.54)$ \\
Gastrointestinal damage & $77(5.39)$ & $51(6.17)$ \\
Musculoskeletal damage & $290(20.31)$ & $168(20.34)$ \\
Osteoporotic fracture damage & $177(12.39)$ & $88(10.65)$ \\
Skin damage & $32(2.24)$ & $21(2.54)$ \\
Gonadal failure damage & $30(2.10)$ & $19(2.30)$ \\
Diabetes damage & $60(4.20)$ & $24(2.91)$ \\
Malignancy damage & $109(7.63)$ & $59(7.14)$ \\
\hline
\end{tabular}

SELENA-SLEDAI score during follow-up and risk of damage was not significant. Being female versus male $(\mathrm{HR}=2.32, \mathrm{p}=0.015)$ or white versus black $(\mathrm{HR}=1.89$, $\mathrm{p}<0.001)$ almost doubled the risk of developing osteoporotic fractures in this patient population. When using corticosteroid as a continuous variable, an increase of prior prednisone dose as minimal as $1 \mathrm{mg} /$ day (irrespective of baseline prednisone dose) was shown to significantly increase the risk of cataracts by $3.8 \%$ and osteoporotic fractures by $4.2 \%$ (data not shown).

Table 3 Time-dependent Cox proportional hazards models for any organ damage

\begin{tabular}{|c|c|c|c|c|c|c|}
\hline \multirow[b]{2}{*}{ Variable } & \multicolumn{2}{|l|}{ Model 1} & \multicolumn{2}{|l|}{ Model 2} & \multicolumn{2}{|l|}{ Model 3} \\
\hline & $\mathrm{HR}(95 \% \mathrm{Cl})$ & p Value & $\mathrm{HR}(95 \% \mathrm{Cl})$ & p Value & $\mathrm{HR}(95 \% \mathrm{Cl})$ & p Value \\
\hline Age at cohort entry & $1.032(1.026$ to 1.038$)$ & $<0.001$ & 1.033 (1.027 to 1.039$)$ & $<0.001$ & 1.032 (1.026 to 1.038$)$ & $<0.001$ \\
\hline Sex (female vs male) & $1.071(0.833$ to 1.377$)$ & 0.592 & $1.089(0.847$ to 1.400$)$ & 0.508 & 1.080 (0.840 to 1.388$)$ & 0.550 \\
\hline \multicolumn{7}{|l|}{ Race } \\
\hline Black (vs White) & $1.113(0.963$ to 1.286$)$ & 0.149 & 1.109 (0.960 to 1.282$)$ & 0.161 & $1.132(0.980$ to 1.307$)$ & 0.091 \\
\hline Asian (vs White) & $0.894(0.541$ to 1.476$)$ & 0.661 & $0.897(0.543$ to 1.482$)$ & 0.672 & 0.908 (0.550 to 1.499$)$ & 0.705 \\
\hline Other (vs White) & 0.879 (0.559 to 1.382$)$ & 0.576 & $0.870(0.553$ to 1.368$)$ & 0.545 & $0.882(0.561$ to 1.387$)$ & 0.587 \\
\hline Year of SLE diagnosis & 0.992 (0.984 to 1.000$)$ & 0.044 & 0.991 (0.983 to 0.998$)$ & 0.018 & 0.989 (0.981 to 0.997$)$ & 0.005 \\
\hline SDI at cohort entry & 1.064 (1.023 to 1.106$)$ & 0.002 & 1.064 (1.024 to 1.107$)$ & 0.002 & 1.064 (1.023 to 1.107$)$ & 0.002 \\
\hline $\begin{array}{l}\text { SELENA-SLEDAI score } \\
\text { during follow-up } \\
\text { ( } \geq 6 \text { vs }<6 \text { ) }\end{array}$ & 1.398 (1.170 to 1.670$)$ & $<0.001$ & 1.370 (1.146 to 1.638$)$ & $<0.001$ & 1.374 (1.149 to 1.642$)$ & $<0.001$ \\
\hline $\begin{array}{l}\text { Immunosuppressant } \\
\text { use during follow-up } \\
\text { (yes vs no) }\end{array}$ & 1.225 (1.046 to 1.434$)$ & 0.012 & 1.209 (1.032 to 1.417$)$ & 0.019 & $1.246(1.068$ to 1.455$)$ & 0.005 \\
\hline $\begin{array}{l}\text { Antimalarial use during } \\
\text { follow-up (yes vs no) }\end{array}$ & $0.926(0.801$ to 1.071$)$ & 0.299 & 0.958 (0.827 to 1.109$)$ & 0.566 & $0.964(0.832$ to 1.116$)$ & 0.623 \\
\hline \multicolumn{7}{|c|}{ Mean prior prednisone dose, mg/day ${ }^{*}$} \\
\hline$(\geq 7.5$ vs $<7.5)$ & 1.742 (1.489 to 2.039$)$ & $<0.001$ & NA & & NA & \\
\hline$(\geq 7.5-<15$ vs $<7.5)$ & NA & & $1.537(1.284$ to 1.840$)$ & $<0.001$ & NA & \\
\hline$(\geq 15-<20$ vs $<7.5)$ & NA & & 1.799 (1.350 to 2.399$)$ & $<0.001$ & NA & $<0.001$ \\
\hline$(\geq 20$ vs $<7.5)$ & NA & & 2.514 (1.977 to 3.196$)$ & $<0.001$ & NA & \\
\hline $1 \mathrm{mg} /$ day & NA & & NA & & $1.028(1.022$ to 1.035$)$ & \\
\hline
\end{tabular}


Table 4 Time-dependent Cox proportional hazards models for any organ damage for inception cohort (patients within the 1 st year of diagnosis $(\mathrm{N}=642)$ and patients within the 2 nd year of diagnosis $(\mathrm{N}=944))$

\begin{tabular}{|c|c|c|c|c|}
\hline \multirow[b]{2}{*}{ Variable } & \multicolumn{2}{|l|}{ Model $4(\mathrm{~N}=642)$} & \multicolumn{2}{|l|}{ Model $5(\mathrm{~N}=944)$} \\
\hline & HR (95\% Cl) & p Value & HR (95\% Cl) & p Value \\
\hline Age at cohort entry & $1.043(1.031$ to 1.056$)$ & $<0.001$ & $1.037(1.027$ to 1.047$)$ & $<0.001$ \\
\hline Sex (female vs male) & 1.033 (0.674 to 1.583$)$ & 0.882 & $1.069(0.759$ to 1.506$)$ & 0.702 \\
\hline \multicolumn{5}{|l|}{ Race } \\
\hline Black (vs White) & $1.067(0.809$ to 1.407$)$ & 0.647 & $1.140(0.911$ to 1.426$)$ & 0.253 \\
\hline Asian (vs White) & $1.041(0.455$ to 2.383$)$ & 0.924 & 0.734 (0.324 to 1.663$)$ & 0.459 \\
\hline Other (vs White) & 1.176 (0.468 to 2.957$)$ & 0.730 & 1.366 (0.726 to 2.569$)$ & 0.334 \\
\hline Year of SLE diagnosis & 0.979 (0.957 to 1.003$)$ & 0.080 & $0.986(0.967$ to 1.006$)$ & 0.164 \\
\hline SDI at cohort entry & $1.043(0.943$ to 1.155$)$ & 0.411 & $1.050(0.968$ to 1.140$)$ & 0.241 \\
\hline SELENA-SLEDAI score during follow-up ( $\geq 6$ vs $<6$ ) & $1.382(0.960$ to 1.989$)$ & 0.082 & $1.328(0.986$ to 1.789$)$ & 0.062 \\
\hline Immunosuppressant use during follow-up (yes vs no) & $1.326(0.969$ to 1.815$)$ & 0.078 & $1.424(1.103$ to 1.837$)$ & 0.007 \\
\hline Antimalarial use during follow-up (yes vs no) & $0.916(0.698$ to 1.201$)$ & 0.525 & $0.923(0.734$ to 1.160$)$ & 0.491 \\
\hline Mean prednisone dose, mg/day ( $\geq 7.5$ vs $<7.5$ ) & 1.834 (1.339 to 2.512$)$ & $<0.001$ & 1.730 (1.338 to 2.236$)$ & $<0.001$ \\
\hline
\end{tabular}

Alternately, from the cardiovascular and the renal models, SELENA-SLEDAI score during follow-up was shown to have a greater impact on risk, as compared with mean prior prednisone dose during follow-up (table 5).

\section{DISCUSSION}

To our knowledge, this is the first study that quantifies the risk of corticosteroid use on overall organ damage or individual organ damage by dose cut-off points endorsed in some SLE clinical trials. This analysis is of significance when attempting to understand the long-term benefit of corticosteroid-sparing agents in the clinical setting. Overall, this study confirmed what has been previously reported on the increased risk of irreversible organ damage associated with corticosteroid use in SLE. ${ }^{2}$ The most important finding of this study was the dose-response relationship between mean prior prednisone dose during follow-up and the risk of developing irreversible organ damage over time. Patients who received, on average, higher prednisone doses $(\geq 7.5 \mathrm{mg} /$ day) during follow-up were significantly more likely to develop any new organ damage over time, compared with those who were exposed, on average, to prednisone doses $<7.5 \mathrm{mg}$ /day after adjustment for disease activity and other variables. Patients in the highest dose subgroup (prednisone dose $\geq 20 \mathrm{mg} /$ day) were more than twice more likely to experience organ damage than those who received $<7.5 \mathrm{mg} /$ day $(\mathrm{HR}=2.514 ; \mathrm{p}<0.001)$. Significant predictors of organ damage other than mean prior prednisone dose during follow-up $(\mathrm{HR}=1.742 ; \mathrm{p}<0.001)$ were recent SELENA-SLEDAI score during follow-up (HR=1.398, $\mathrm{p}<0.001)$; immunosuppressant use during follow-up $(\mathrm{HR}=1.225 ; \mathrm{p}=0.012)$; SDI score at cohort entry $(\mathrm{HR}=1.064 ; \mathrm{p}=0.002)$; age at cohort entry $(\mathrm{HR}=1.032$; $\mathrm{p}<0.001)$; and year of SLE diagnosis $(\mathrm{HR}=0.992 ; \mathrm{p}=0.044)$ (Model 1). The sensitivity analyses completed using the inception cohort(s) were consistent with the findings of the overall model $(\mathrm{N}=2199)$ for any new organ damage, where corticosteroid was a significant predictor of the risk of any new organ damage over time while adjusting for important confounders (table 4).

Previous analysis from the Hopkins Lupus Cohort has demonstrated a reduced risk of organ damage associated with average cumulative doses of prednisone $<6 \mathrm{mg}$ / day. ${ }^{3}$ In this analysis, we estimated the impact of average prednisone dose as a continuous variable (rather than a discrete variable) and we quantified the risk associated with an increase in average daily prednisone dose of $1 \mathrm{mg} /$ day $(\mathrm{HR}=1.028 ; \mathrm{p}<0.001)$, irrespective of baseline prednisone dose (table 3). These data on the risk of damage associated with an increase in average prednisone dose of $1 \mathrm{mg} /$ day and $5 \mathrm{mg} /$ day $(\mathrm{HR}=1.150$, $\mathrm{p}<0.001)$ may help inform the clinical decision-making process for corticosteroid dose tapering in SLE. Successful corticosteroid tapering below levels of $5 \mathrm{mg}$ / day is possible with low levels of disease activity (SELENA-SLEDAI 0-2), ${ }^{5}$ highlighting the significantly great unmet need for corticosteroid-sparing therapies that simultaneously reduce disease activity in SLE.

Another significance of this study is that it demonstrates the risk associated with corticosteroids on individual organ systems within the same study cohort, which further provides insight into the types of damage that are more likely to occur first over time. Daily prednisone doses $\geq 7.5 \mathrm{mg}$ increased the risk of developing cataracts, osteoporotic fractures and cardiovascular damage, but not renal damage. The relative impact of corticosteroid use on cataracts, osteoporotic fractures and cardiovascular damage varied as is evident by the different effect size values (HR values) for these different types of organ damage (table 5). The effect size value was higher for cataracts than for osteoporotic fractures and for cardiovascular damage. 
Table 5 Time-dependent Cox proportional hazards models for cataracts, osteoporotic fractures, cardiovascular damage and renal damage

\begin{tabular}{|c|c|c|}
\hline Parameter & $\mathrm{HR}(95 \% \mathrm{Cl})$ & p Value \\
\hline \multicolumn{3}{|l|}{ Cataracts } \\
\hline Age at cohort entry & $1.065(1.053$ to 1.077$)$ & $<0.001$ \\
\hline \multicolumn{3}{|l|}{ Sex } \\
\hline Female vs Male & 1.549 (0.892 to 2.691$)$ & 0.120 \\
\hline \multicolumn{3}{|l|}{ Race } \\
\hline Black vs White & $1.045(0.771$ to 1.416$)$ & 0.775 \\
\hline Asian vs White & 1.449 (0.632 to 3.325$)$ & 0.381 \\
\hline Other vs White & 0.919 (0.336 to 2.517$)$ & 0.870 \\
\hline SDI at cohort entry & $1.004(0.923$ to 1.091$)$ & 0.931 \\
\hline Year of SLE diagnosis & $1.012(0.995$ to 1.028$)$ & 0.157 \\
\hline \multicolumn{3}{|c|}{ Mean prior prednisone dose during follow-up, $\mathrm{mg} / \mathrm{day}$} \\
\hline$\geq 7.5$ vs $<7.5$ & 2.412 (1.778 to 3.273$)$ & $<0.001$ \\
\hline \multicolumn{3}{|l|}{ SELENA-SLEDAI score } \\
\hline$\geq 6$ vs $<6$ & 1.475 (1.008 to 2.157$)$ & 0.045 \\
\hline \multicolumn{3}{|l|}{ Osteoporotic fractures } \\
\hline Age at cohort entry & $1.042(1.030$ to 1.055$)$ & $<0.001$ \\
\hline \multicolumn{3}{|l|}{ Sex } \\
\hline Female vs Male & 2.320 (1.174 to 4.585$)$ & 0.015 \\
\hline \multicolumn{3}{|l|}{ Race } \\
\hline Black vs White & $0.529(0.379$ to 0.740$)$ & $<0.001$ \\
\hline Asian vs White & 0.438 (0.108 to 1.783$)$ & 0.249 \\
\hline Other vs White & $1.074(0.434$ to 2.659$)$ & 0.877 \\
\hline SDI at cohort entry & $1.043(0.958$ to 1.136$)$ & 0.332 \\
\hline Year of SLE diagnosis & $0.992(0.975$ to 1.010$)$ & 0.378 \\
\hline \multicolumn{3}{|l|}{ Immunosuppressant use } \\
\hline Yes vs No & $1.490(1.078$ to 2.059$)$ & 0.016 \\
\hline \multicolumn{3}{|c|}{ Mean prior prednisone dose during follow-up (mg/day) } \\
\hline$\geq 7.5$ vs $<7.5$ & 2.161 (1.546 to 3.022$)$ & $<0.001$ \\
\hline \multicolumn{3}{|l|}{ SELENA-SLEDAI score } \\
\hline$\geq 6$ vs $<6$ & $1.055(0.676$ to 1.646 & 0.813 \\
\hline \multicolumn{3}{|l|}{ Cardiovascular damage } \\
\hline Age at cohort entry & $1.048(1.032$ to 1.063$)$ & $<0.001$ \\
\hline \multicolumn{3}{|l|}{ Sex } \\
\hline Female vs Male & 0.531 (0.306 to 0.924$)$ & 0.025 \\
\hline \multicolumn{3}{|l|}{ Race } \\
\hline Black vs White & 0.854 (0.569 to 1.284$)$ & 0.449 \\
\hline Asian vs White & 2.875 (1.129 to 7.317$)$ & 0.027 \\
\hline Other vs White & 1.169 (0.359 to 3.802$)$ & 0.796 \\
\hline SDI at cohort entry & 1.166 (1.067 to 1.273$)$ & $<0.001$ \\
\hline Year of SLE diagnosis & 0.984 (0.964 to 1.004$)$ & 0.112 \\
\hline \multicolumn{3}{|c|}{ Mean prior prednisone dose during follow-up, $\mathrm{mg} / \mathrm{day}$} \\
\hline$\geq 7.5$ vs $<7.5$ & $1.544(1.018$ to 2.341$)$ & 0.041 \\
\hline \multicolumn{3}{|l|}{ SELENA-SLEDAI score } \\
\hline$\geq 6$ vs $<6$ & 2.737 (1.780 to 4.209$)$ & $<0.001$ \\
\hline \multicolumn{3}{|l|}{ Antimalarials } \\
\hline Yes vs No & 0.898 (0.605 to 1.333$)$ & 0.593 \\
\hline \multicolumn{3}{|l|}{ Hypertension } \\
\hline Yes vs No & 2.322 (1.267 to 4.257 ) & 0.006 \\
\hline \multicolumn{3}{|l|}{ Diabetes } \\
\hline Yes vs No & $0.832(0.257$ to 2.689$)$ & 0.758 \\
\hline Renal damage & & \\
\hline Yes vs No & 2.229 (1.133 to 4.384$)$ & 0.020 \\
\hline BMI & 1.005 (0.981 to 1.030$)$ & 0.668 \\
\hline Cholesterol & 1.004 (1.000 to 1.007$)$ & 0.039 \\
\hline Renal damage & & \\
\hline Age at cohort entry & 0.998 (0.978 to 1.017$)$ & 0.814 \\
\hline
\end{tabular}




\begin{tabular}{|c|c|c|}
\hline Parameter & HR (95\% Cl) & p Value \\
\hline \multicolumn{3}{|l|}{ Sex } \\
\hline Female vs Male & $0.595(0.288$ to 1.226$)$ & 0.159 \\
\hline \multicolumn{3}{|l|}{ Race } \\
\hline Black vs White & $1.694(1.023$ to 2.804$)$ & 0.041 \\
\hline Asian vs White & $1.547(0.361$ to 6.626$)$ & 0.556 \\
\hline Other vs White & $3.347(1.130$ to 9.911$)$ & 0.029 \\
\hline SDI at cohort entry & $1.126(1.010$ to 1.255$)$ & 0.032 \\
\hline Year of SLE diagnosis & $0.974(0.950$ to 0.998$)$ & 0.036 \\
\hline \multicolumn{3}{|l|}{ Immunosuppressant use } \\
\hline Yes vs No & $1.040(0.623$ to 1.737$)$ & 0.879 \\
\hline \multicolumn{3}{|c|}{ Mean prior prednisone dose during follow-up, mg/day } \\
\hline$\geq 7.5$ vs $<7.5$ & $1.440(0.863$ to 2.403$)$ & 0.163 \\
\hline \multicolumn{3}{|l|}{ SELENA-SLEDAI score } \\
\hline$\geq 6$ vs $<6$ & 4.079 (2.521 to 6.600$)$ & $<0.001$ \\
\hline \multicolumn{3}{|l|}{ Antimalarials } \\
\hline Yes vs No & $0.449(0.270$ to 0.749$)$ & 0.002 \\
\hline \multicolumn{3}{|l|}{ Hypertension } \\
\hline Yes vs No & 2.157 (0.912 to 5.102$)$ & 0.080 \\
\hline
\end{tabular}

When evaluating mean prednisone dose as a continuous measure for the cataract and osteoporotic fracture models, we estimated that an increase in average prednisone dose of $1 \mathrm{mg} /$ day was associated with the increased risk of cataracts by $3.8 \%$ and osteoporotic fractures by $4.2 \%$. Furthermore, our data demonstrated that the most frequent types of organ damage to first occur over time were musculoskeletal damage and ocular damage (cataracts), the rates of which may potentially be attenuated by the use of corticosteroid-sparing agents in SLE (table 2).

The findings from this study are representative of a well-controlled patient population with SLE (mean SELENA-SLEDAI score at baseline was 3.5) with relatively lower exposure to corticosteroids over time. We do not know how these data may compare with other patients with SLE across the USA; however, we believe that the results of this study may represent one of the most conservative estimates of the rates of organ damage in SLE to date, given the smaller percentage of patients receiving higher doses on prednisone $(\geq 7.5 \mathrm{mg} /$ day) over time (from the Hopkins cohort, the proportion of patients on prednisone $\geq 7.5 \mathrm{mg}$ /day had declined from $57.4 \%$ since 1987 to $11.2 \%$ as of 2012). Furthermore, there are short-term side effects associated with varied levels of exposure to corticosteroids that were not explored in this study, including the risk of infections. Considering all these factors together, the burden imposed by corticosteroid use in SLE is important. Clearly, there is an urgent need for corticosteroidsparing therapies that also better control SLE disease activity. A reduction of as little as $1 \mathrm{mg} /$ day or $5 \mathrm{mg}$ /day in mean prednisone dose would have benefits and potential healthcare savings based on our analyses.
Evaluation of non-corticosteroid therapies that manage disease activity and symptoms but avoid the adverse effects of corticosteroids (including but not limited to organ damage) is required to improve the treatment of patients with SLE. Corticosteroid-sparing agents would potentially decrease the risk of these corticosteroidrelated comorbidities in a rather young patient population and subsequently decrease the healthcare costs needed to manage these conditions over time.

There are limitations to this study. In the Hopkins Lupus Cohort, measures of treatment adherence or compliance between quarterly patients' visits were not available; thus, our analyses were based on the assumption that the corticosteroid dose was constant for the quarter after each person-quarter record. Furthermore, the analyses were based on the assumption that those who are censored are not different, on average, from those who are not censored with respect to the relationship between predictors and damage rates, after adjustment for other variables in the Cox models. This seems like a reasonable assumption given the fact that dropouts occur for many reasons. However, if this assumption does not hold, our estimates could be somewhat biased.

Disease activity is a predictor of damage, and prednisone reduces disease activity; therefore, prednisone might have some benefit on preventing some types of organ damage due to SLE alone. For this reason, the HRs reported, while clinically important, are not pure estimates of the impact of prednisone.

In conclusion, understanding the overall risk of organ damage and risk at individual organ systems associated with exposure to high-dose prednisone over time (ie, $\geq 7.5 \mathrm{mg}$ /day) and further understanding the risk imposed by an average of a $1 \mathrm{mg} /$ day or $5 \mathrm{mg} /$ day 
increase in prednisone dose would help clinicians better understand the long-term benefit gained from the use of corticosteroid-sparing therapies that are currently in development in SLE clinical trials.

Acknowledgements The authors thank Jeffrey Walter and Maria Rovere, of inVentiv Health Clinical (funded by Eli Lilly and Company), for assistance in writing and editing this manuscript, respectively.

Contributors SAS, XZ, BZ, SAF and NI designed the study, performed the analyses and drafted the manuscript. All authors reviewed, revised and approved the final content of the manuscript.

Funding The Hopkins Lupus Cohort is supported by NIH R01AR043727. Funding for this study analysis was sponsored by Eli Lilly and Company.

Competing interests SAS, XZ, BZ, SAF, and NI are employees and stockholders of Eli Lilly and Company. LM and MP have nothing to declare.

Ethics approval Johns Hopkins University School of Medicine Institutional Review Board for the Hopkins Lupus Cohort.

Provenance and peer review Not commissioned; externally peer reviewed.

Data sharing statement Additional information about the data set and analyses are available upon request, but the data files are the proprietary property of Eli Lilly and Company.

Open Access This is an Open Access article distributed in accordance with the Creative Commons Attribution Non Commercial (CC BY-NC 4.0) license, which permits others to distribute, remix, adapt, build upon this work noncommercially, and license their derivative works on different terms, provided the original work is properly cited and the use is non-commercial. See: http:// creativecommons.org/licenses/by-nc/4.0/

\section{REFERENCES}

1. Petri M, Purvey S, Fang $\mathrm{H}$, et al. Predictors of organ damage in systemic lupus erythematosus: the Hopkins Lupus Cohort. Arthritis Rheum 2012;64:4021-8
2. Gladman DD, Urowitz MB, Rahman PP, et al. Accrual of organ damage over time in patients with systemic lupus erythematosus. $J$ Rheumatol 2003;30:1955-9.

3. Thamer M, Hernán MA, Zhang Y, et al. Prednisone, lupus activity, and permanent organ damage. J Rheumatol 2009;36:560-4.

4. Magder L, Petri M. Incidence of and risk factors for adverse cardiovascular events among patients with systemic lupus erythematosus. Am J Epidemiol 2012;176:708-19.

5. Zahr ZA, Fang H, Magder LS, et al. Predictors of corticosteroid tapering in SLE patients: the Hopkins Lupus Cohort. Lupus 2013;22:697-701.

6. Gladman D, Ginzler E, Goldsmith C, et al. The development and initial validation of the Systemic Lupus International Collaborating Clinics/American College of Rheumatology Damage Index for systemic lupus erythematosus. Arthritis Rheum 1996;39:363-9.

7. Gladman DD, Urowitz $\mathrm{MB}$, Goldsmith $\mathrm{CH}$, et al. The reliability of the Systemic Lupus International Collaborating Clinics/American College of Rheumatology Damage Index in patients with systemic lupus erythematosus. Arthritis Rheum 1997;40:809-13.

8. Zonana-Nacach A, Camargo-Coronel A, Yáñez P, et al. Measurement of damage in 210 Mexican patients with systemic lupus erythematosus: relationship with disease duration. Lupus 1998;7:119-23.

9. Sutcliffe N, Clarke AE, Gordon C, et al. The association of socioeconomic status, race, psychological factors, and outcome in patients with systemic lupus erythematosus. Rheumatology (Oxford) 1999;38:1130-7.

10. Nossent JC. SLICC/ACR Damage Index in Afro-Caribbean patients with systemic lupus erythematosus: changes in and relationship to disease activity, corticosteroid therapy, and prognosis. J Rheumatol 1998;25:654-9.

11. Mok CC, Lee KW, Ho CT, et al. A prospective study of survival and prognostic indicators of systemic lupus erythematosus in a southern Chinese population. Rheumatology (Oxford) 2000;39:399-406.

12. Yee $\mathrm{C}$, Hussein $\mathrm{H}$, Skan $\mathrm{J}$, et al. Association of damage with autoantibody profile, age, race, sex, and disease duration in systemic lupus erythematosus. Rheumatology (Oxford) 2003;42:276-9.

13. Petri M, Kim MY, Kalunian KC, et al. Combined oral contraceptives in women with systemic lupus erythematosus. New Engl J Med 2005;353:2550-8. 